\title{
Clinical observation of the application of autologous peripheral blood stem cell transplantation for the treatment of diabetic foot gangrene
}

\author{
SHI-MIN XU ${ }^{1}$ and TING LIANG ${ }^{2}$ \\ ${ }^{1}$ Department of Orthopedics, Weifang People's Hospital, Weifang, Shandong 261041; \\ ${ }^{2}$ Department of Administration, People's Hospital of Langfang, Langfang, Hebei 065000, P.R. China
}

Received September 23, 2014; Accepted August 20, 2015

DOI: $10.3892 / \mathrm{etm} .2015 .2888$

\begin{abstract}
The aim of the present study was to investigate the optimal mobilization plan in autologous peripheral blood stem cell transplantation for the treatment of diabetic foot and to observe its clinical curative effect. A total of 127 patients with diabetic foot were treated with different doses of granulocyte colony stimulating factor (G-CSF) to mobilize their hematopoietic stem cells. Subsequently, the extracted stem cell suspension was injected into the ischemic lower extremities along the blood vessels in the areas presenting with pathological changes. Following the treatment, the intermittent claudication distance, skin temperature, ankle brachial index and pain scores of the patients were evaluated. In addition, the associations among the mobilization time, doses and peripheral blood $\mathrm{CD} 4^{+}$level were analyzed. The collection efficiency of the stem cells was associated with the dose of G-CSF and the mobilization time. Following the injection of the autologous peripheral blood stem cell suspension, the ischemic area of the patients was improved significantly. In conclusion, autologous peripheral blood stem cell transplantation can promote the establishment of collateral circulation in patients with diabetic foot, and the optimal time for gathering stem cells is closely correlated with the peripheral blood CD $34^{+}$level.
\end{abstract}

\section{Introduction}

Currently, the incidence of diabetes is increasing rapidly, leading to more cases of diabetic foot. Diabetic foot is predominantly observed in males and elderly patients $>60$ years of age (1). It has been reported that the incidence rate of diabetic foot over the lifetime of a patient with diabetes is $15-25 \%$ (2).

Correspondence to: Dr Shi-Min Xu, Department of Orthopedics, Weifang People's Hospital, 151 Guangwen Road, Weifang, Shandong 261041, P.R. China

E-mail: shiminxu@126.com

Key words: autologous peripheral blood stem cells, stem cell mobilization, diabetic foot, gangrene, $\mathrm{CD} 34^{+}$
Diabetic foot is a chronic and progressive lesion, involving blood vessels, nerves, tendons and bone $(3,4)$. Sclerosis, stenosis or occlusion in the arteries of the lower extremities may affect blood supply to the limbs, particularly the acral skin, frequently leading to ulcers and gangrene. Foot infection and gangrene may result in amputation and disability, while certain patients may succumb to the condition. Traditionally, the treatment of diabetic foot consists primarily of medical pharmacotherapy or surgical reconstruction of blood flow; however, for patients with diabetic foot caused by arterial occlusion, medication cannot fundamentally solve the underlying cause of the condition. In addition, the lesions in the lower extremities of such patients are typically segmental and involve the arteries of the leg; due to the absence of the distal artery flow tract, such patients may not be able to undergo an artery bypass or vascular interventional treatment (5).

Recently, stem cell transplantation technology has been increasingly studied worldwide, and human stem cell studies have become a crucial new field in the life sciences. The emergence of stem cell transplantation is among the most important developments in life sciences at the end of the 20th century (6). In 1998, Thomson et al (7) isolated human embryonic stem cells from the inner cell mass and observed that these cells possessed self-renewal and multi-directional differentiation potentials in vitro and in vivo. Stem cells have subsequently become a key research tool in the biomedical sciences, and show promise for the treatment of various intractable diseases. It has been demonstrated that hematopoietic stem cells can be induced to differentiate into vascular endothelial cells via exposure to ischemic and anoxic environments (8), which promotes neovascularization in the ischemic limb and improves blood supply, thereby treating limb ischemia $(9,10)$. In autologous stem cell transplantation for the treatment of lower-limb ischemic diseases, the majority of studies have used granulocyte colony stimulating factor (G-CSF) at doses of 5 and $10 \mu \mathrm{g} / \mathrm{kg} /$ day for the stem cell mobilization, and the stem cells have been harvested after 5 days; however, whether this is the optimal mobilization and harvesting time has not yet been verified $(11,12)$. The aim of the present study was to observe the mobilization effect of autologous hematopoietic stem cells by applying different doses of G-CSF at different times, in order to determine the optimal dose of G-CSF and 
the optimal time for stem cell mobilization. Furthermore, the clinical curative effect of autologous peripheral blood stem cell transplantation in the treatment of diabetic foot gangrene was investigated.

\section{Materials and methods}

Clinical data. A total of 127 patients with diabetic foot necrosis, including 58 males and 69 females (mean age, 69 years; age range, $49-84$ years) were enrolled in this study. This study was conducted in accordance with the Declaration of Helsinki and with approval from the Ethics Committee of Weifang People's Hospital (Weifang, China). Written informed consent was obtained from all participants. All patients presented with degree 3 to 4 diabetic foot, and 98 patients exhibited pain at rest and/or intermittent claudication (13). All patients presented with different degrees of acral gangrene and ischemic ulcers and/or pain at rest. The patients were eager to be relieved of the intermittent claudication. A preoperative digital subtraction angiography (DSA) examination confirmed the presence of occlusive lesions in the main vessels of the patients. All cases met the World Health Organization diagnostic criteria for diabetic foot (14). Cases complicated with seriously impaired function of the heart, lungs, brain, kidney and other organs or patients who could not tolerate the surgery were excluded.

Hematopoietic stem cell mobilization. A total of 127 patients were divided into 2 groups at random. Group A $(n=63)$ received subcutaneous injections of $5 \mu \mathrm{g} / \mathrm{kg} /$ day recombinant human G-CSF (Filgrastim; Sandoz Pharmaceuticals GmbH, Holzkirchen, Germany), twice per day. In group A, 16 patients were treated for 4 days, 17 patients for 5 days, 16 cases for 6 days and 14 cases for 7 days. Group B $(n=64)$ received subcutaneous injections of $10 \mu \mathrm{g} / \mathrm{kg} /$ day Filgrastim, twice per day. In group B, 16 patients received treatment for 4 days, 17 patients for 5 days, 16 patients for 6 days and 15 patients for 7 days. The peripheral blood mononuclear cells (PBMNCs) and $\mathrm{CD} 34^{+}$cells were counted each day. When the PBMNC count and $\mathrm{CD} 4^{+}$cell number reached a peak, peripheral blood stem cells were collected. During the G-CSF mobilization, low-molecular-weight heparin (5,000 IU; Sanofi-Aventis S.A., Paris, France) was administered by subcutaneous injection every day, in order to prevent a cerebrovascular accident induced by the increased leukocyte count.

Collection of hematopoietic stem cells. Venous blood was collected from the median cubital vein of one of the upper extremities and directly entered into a blood cell separator (Fresenius SE \& Co. KGaA, Bad Homburg, Germany) through a closed system. Subsequently, $\sim 50 \mathrm{ml}$ stem cell suspension was filtered out, and the remaining blood was transfused back to the patient via the median cubital vein of the other upper extremity simultaneously. If necessary in certain patients, the great saphenous vein or subclavian vein was used for puncture and catheterization.

Determination of white blood cells (WBCs), PBMNCs and CD $34^{+}$cells. WBCs and PBMNCs were counted using an automatic blood analyzer (Beckman Coulter, Brea, CA, USA), and the peripheral blood $\mathrm{CD} 34^{+}$cells prior to and following G-CSF mobilization were detected using a flow cytometer, $\mathrm{CD} 34^{+}$monoclonal antibodies and a hemolytic agent (BD Biosciences, Franklin Lakes, NJ, USA), according to the manufacturer's instructions.

Autologous peripheral blood stem cell transplantation. Air disinfection of the operating theater was performed for $30 \mathrm{~min}$ prior to transplantation. Simultaneously, patients received an intramuscular injection of $100 \mathrm{mg}$ pethidine hydrochloride (Shenyang First Pharmaceutical Factory, Shenyang, China) for analgesia. Following disinfection of the limb skin, stem cell suspension fluid was injected into the ischemic lower extremities at multiple points around the embolized blood vessels, using a $23 \mathrm{G}$ syringe. The puncture positions were pre-marked between the foot and $3 \mathrm{~cm}$ above the knee, with intervals of $3 \mathrm{~cm}$. Subsequently, $2 \mathrm{ml}$ stem cell suspension fluid was injected into each marker point. For the ulcerated or necrotic areas, the stem cell suspension fluid was injected around or at the bottom of the lesion tissues by point injection. Following the transplantation, the affected extremity received a protective pressure dressing.

Intermittent claudication distance $(L)$ scoring. The distance that the patient could walk prior to experiencing claudication was scored as follows: 0 points, $L \geq 0.5 \mathrm{~km}$ with no pain; 1 point, $0.499 \geq \mathrm{L} \geq 0.4 \mathrm{~km}$ with pain; 2 points, $0.399 \geq \mathrm{L} \geq 0.3 \mathrm{~km}$ with pain; 3 points, $0.299 \geq \mathrm{L} \geq 0.1 \mathrm{~km}$ with pain; and 4 points, pain at rest and unable to walk, or walking distance $<0.1 \mathrm{~km}$.

Skin temperature measurement. Skin temperature was measured at the skin outside the third metatarsophalangeal joint at the dorsum of foot using an SDW point digital thermometer (Tianjin Traffic Electronic Instrument Experimental Factory, Tianjin, China). Temperatures were measured and recorded at the same time each day in all patients.

Ankle brachial index (ABI) measurement. ABI was detected using a Doppler flow detector and ABI check equipment (Beijing Gelin Dimei Technology Co., Ltd., Beijing, China).

Pain scoring. Patient pain was scored as follows: 0 points, no pain; 1 point, mild and tolerable pain with no analgesic drugs required; 2 points, moderate pain requiring oral analgesic drugs; and 3 points, severe pain that was not relieved by general analgesic drugs and required an analgesic injection.

DSA imaging of the lower extremities. DSA of the lower extremities was performed using a Siemens Duplex computer imaging system (Siemens Healthcare, Erlangen, Germany) and the resulting images were scored as followed: 0 points, no new collateral vessels; 1 point, little new collateral circulation; 2 points, moderate new collateral circulation; 3 points, abundant new collateral circulation.

Statistical analysis. Data are presented as the mean \pm standard deviation and were analyzed using SPSS statistical software, version 19.1 (IBM SPSS, Armonk, NY, USA). Comparisons between the data prior to and following the treatment were performed using the paired $t$-test. $\mathrm{P}<0.05$ was considered to indicate a statistically significant difference. 
Table I. Comparisons of the evaluation indicators of the patients with diabetes prior to and following stem cell transplantation.

\begin{tabular}{|c|c|c|c|c|}
\hline Parameter & Pre-transplantation & Post-transplantation $^{a}$ & $t$ value & P-value \\
\hline Intermittent claudication score & $3.31 \pm 0.62$ & $1.17 \pm 0.66$ & 7.630 & $<0.01$ \\
\hline Skin temperature $\left({ }^{\circ} \mathrm{C}\right)$ & $31.45 \pm 1.36$ & $32.11 \pm 1.23$ & 7.625 & $<0.01$ \\
\hline Ankle brachial index & $0.28 \pm 0.98$ & $0.50 \pm 0.12$ & -9.427 & $<0.01$ \\
\hline Pain score & $2.30 \pm 0.89$ & $1.79 \pm 0.38$ & -3.539 & $<0.01$ \\
\hline CTA score & $1.22 \pm 0.15$ & $2.35 \pm 0.784$ & 6.348 & $<0.01$ \\
\hline
\end{tabular}

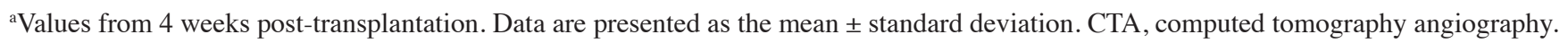

\section{Results}

Collection efficiency of stem cells is closely correlated with the dosage and mobilization time of G-CSF. With the prolongation of the hematopoietic stem cell mobilization time, the WBC and PBMNC counts and the number of CD34+ cells increased; however, the WBC count normalized by day 3 after the mobilization was ceased. The WBC counts of groups A and $\mathrm{B}$ reached $3.0 \times 10^{10} / 1$ at days 4 and 3 of mobilization, respectively. Furthermore, the PBMNC count and $\mathrm{CD} 34^{+}$cell number of groups A and B peaked at days 5 and 4, respectively. On the fourth day of mobilization, the PBMNC count of group B was $(5.59 \pm 1.63) \times 10^{9} / 1$ and the $\mathrm{CD} 34^{+}$cell number was $(3.57 \pm 1.56) \times 10^{7} / 1$; on the fifth day of mobilization, the PBMNC count of group A was $(5.72 \pm 1.56) \times 10^{9} / 1$ and the $\mathrm{CD} 34^{+}$cell number was $(4.26 \pm 1.21) \times 10^{7} / 1$. All patients in groups $\mathrm{A}$ and $\mathrm{B}$ met the requirements for the stem cell collection. Therefore, In group A, 16 cases underwent stem cell collection on day 4, 17 cases on day 5,16 cases on day 6 and 14 cases on day 7 . In group B, 16 cases underwent stem cell collection on day 4 , 17 cases on day 5,16 cases on day 6 and 15 cases on day 7 . The $\mathrm{CD}_{3}{ }^{+}$cell number increased with the increase in PBMNCs, and a positive correlation was detected between these parameters $(r=0.626, \mathrm{P}<0.05)$.

Blood circulation in the ischemic area. At the early stage after injection with stem cell suspension, the local skin temperature of the patients increased significantly and blood oozing from the wound surface increased. Granulation occurred at a significantly more rapid rate, and patients experienced a local burning pain. After 4 weeks, patients were followed-up for a DSA re-examination. DSA indicated that the collateral circulation in the affected lower extremity was established. The volume of blood flow to the acral skin increased markedly compared with that prior to transplantation. Local pain was alleviated and the patients felt improvements in their condition. The numbness disappeared and the intermittent claudication symptom was improved. In addition, patients were able to walk for increased distances (Table I).

Report of a typical case. Patient A was a 75 year-old male with a 32-year history of diabetes, who was admitted to the Weifang People's Hospital due to a left diabetic foot gangrene concurrent infection (Fig. 1A). Preoperative lower-extremity DSA showed that the blood vessels below the popliteal artery branch were occluded extensively with no distal outflow; however, small amounts of local collateral circulation remained (Fig. 2A). The patient additionally exhibited coronary heart disease, hypertension, cerebrovascular disease, transient ischemic attack and cerebral infarction. Patient $\mathrm{A}$ was thus unable to undergo amputation. Following extensive debridement, the patient received the autologous peripheral blood stem cell transplantation. After 3 weeks, fresh granulation growth was observed when the patient returned to the hospital for further debridement (Fig. 1B). The patient subsequently underwent an in situ dermatoplasty. At 2 weeks after this skin graft, the wounds appeared to be healing well (Fig. 1C). Postoperative CTA examination showed that extensive collateral circulation was widely established along the lesion vessels (Fig. 2B). At a 3-year follow-up examination, the local wound of the patient was observed to have healed well and the walking function of the lower extremities was predominantly maintained.

\section{Discussion}

When the body is in an ischemic state, new blood vessels are generated as a compensatory mechanism. This neoangiogenesis includes two key processes: Angiogenesis and vascularization. Vascularization refers to the generation of new blood vessels through the differentiation and interaction of endothelial progenitor cells (EPCs) and hematopoietic stem cells, in environments with no original vascular system. It is conventionally believed that the further differentiation of EPCs into vascular endothelial cells to form a new vascular system does not occur in vivo following birth. In 1997, however, Asahara et al (15) observed that EPCs are present in the blood circulation, exhibiting chemotaxis and homing abilities to the ischemic tissues and differentiating to form new blood vessels. These results verified the existence of 'postnatal vascularization'. Ischemic animal model studies indicate that endothelial progenitor cells are able to enter a vascularizing area and increase the generation of collateral vessels in ischemic tissues (16-18).

In 1997, Asahara et al (15) were the first to identify that peripheral blood $\mathrm{CD}^{+} 4^{+}$and vascular endothelial growth factor receptor $2^{+}\left(\mathrm{VEGFR}-2^{+}\right)$cells are able to proliferate in vitro and transform into vascular endothelial cells. It has subsequently been generally accepted that CD133+, VEGFR-2 ${ }^{+}$ and $\mathrm{CD}_{34^{+}}$bone marrow-derived cells possess the ability to differentiate into EPCs (19). During the differentiation of such cells, the expression of CD133 is gradually downregulated and the expression levels of CD31, von Willebrand factor 

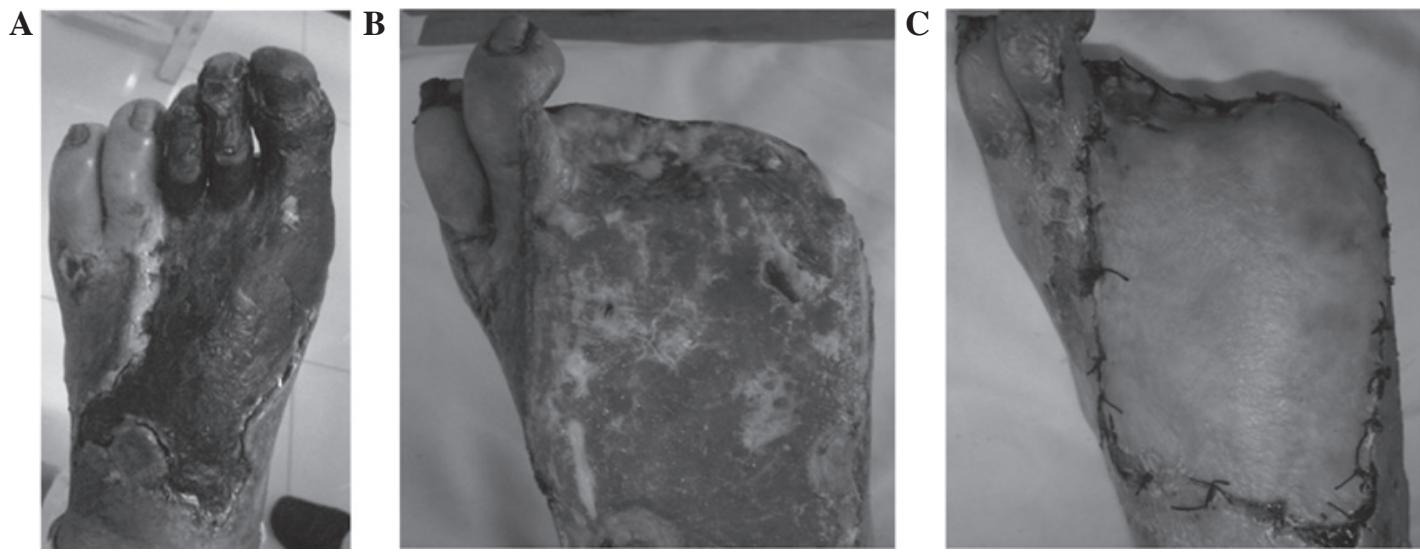

Figure 1. Gangrenous wound of a single diabetic foot patient successfully healed following the autologous peripheral blood stem cell transplantation (A) Preoperative diabetic foot of patient A, showing extensive necrosis and co-infection at left foot. (B) Diabetic foot of patient A at 3 weeks after stem cell transplantation; fresh granulation growth was evident in the wound. (C) Foot of patient A at 4 weeks after transplantation following an in situ dermatoplasty, with the wound healing well.

A

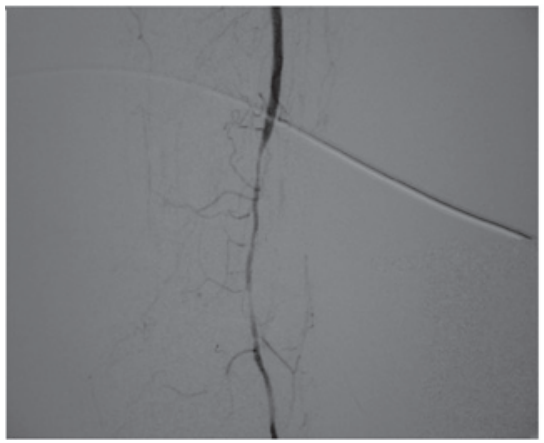

B

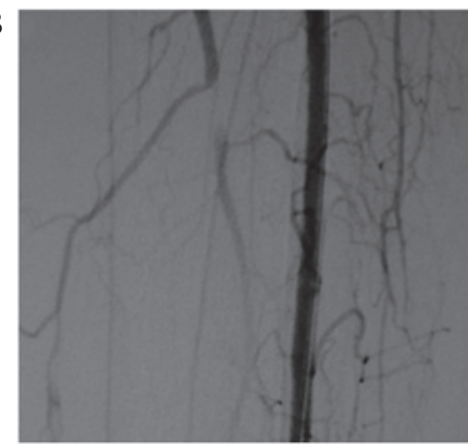

Figure 2. Digital subtraction angiography (DSA) images showing changes in the patient's vessels prior to and following stem cell transplantation. (A) Preoperative DSA of patient A showing that the main vessels were occluded and few collateral vessels remained. (B) At 6 weeks after the transplantation, DSA re-examination showed that abundant collateral circulation had been established around the blood vessels in the lesion area.

and cadherin in vascular endothelial cells increase gradually, facilitating the formation of mature endothelial cells (20).

It is currently believed that vascularization and angiogenesis coexist in the embryonic development period, in addition to participating in numerous physiological and pathological processes following birth (21). These processes are involved in the dynamic maintenance and physiological reconstruction of blood vessels and are dependent on the postnatal angiogenic activity of EPC. The concept of 'therapeutic angiogenesis' refers to the application of exogenous vasoformative factors and/or the transfusion of vasoformative cells into ischemic tissues to promote angiogenesis and the formation of collateral vessels, in order to improve blood supply and treat ischemic diseases (22). This therapeutic approach is a physiological strengthening treatment, which utilizes the presence of EPCs in the adult blood circulation and the fact that these EPCs exhibit the biological characteristics of chemotaxis and homing abilities to ischemic tissues, as well as their differentiation to form new blood vessels.

Stem cell transplantation may involve a variety of cell types, including autologous peripheral blood, bone marrow mesenchymal (23), autologous bone marrow (24) and umbilical cord blood $(25,26)$ stem cells. The collection of bone marrow requires epidural anesthesia or general anesthesia and is more stressful for the general condition of a patient. In addition, large quantities of bone marrow $(\leq 500 \mathrm{ml})$ may be required, and therefore certain patients are physically and psychologically unable to undergo this treatment. In recent years, studies concerning autologous peripheral blood stem cell transplantation have achieved marked progress (27-29). The autologous peripheral blood stem cell transplantation procedure is simple and readily accepted by patients. In order to increase the content of stem cells and improve the curative effect of stem cell transplantation, recombinant human G-CSF can be used to stimulate the proliferation of bone marrow stem cells and promote their release into the peripheral blood. Recently, the wide application of cytokines and blood cell separation techniques has facilitated the mobilization of bone marrow hematopoietic stem cells into the peripheral blood circulation, as well as their purification. Due to the mobilization of bone marrow, blood cell separation and centrifugal concentration, the concentration and number of stem cells available for use in treatment have been markedly increased. In the present study, following peripheral blood stem cell transplantation, symptoms including pain, cold sensations in the affected limb, intermittent claudication and ulcers were notably improved. At 1 month after transplantation, the peripheral blood flow amplitude and blood perfusion volume, detected by laser Doppler scanning, were improved significantly compared with the results prior to the transplantation. DSA imaging of the lower artery showed that new collateral vessel 
formation had increased significantly. Based on the comprehensive assessment of the indicators of the patients prior to and following stem cell transplantation, the present study indicates that autologous peripheral blood stem cell transplantation is able to effectively increase the blood flow in the lower limbs, which may permit certain patients to avoid amputation or reduce the height along the limb at which amputation is conducted.

Stem cells are predominantly located in the bone marrow. Stem cells in the peripheral blood are equivalent to $0.1-1 \%$ of the stems cells in the bone marrow, and CD $34^{+}$cells account for $0.01-0.1 \%$ of PBMNCs. In order to increase the content of stem cells, G-CSF is used to stimulate the proliferation of stem cells in the bone marrow and subsequently promote their release into the peripheral blood. This is the primary method used in stem cell transplantation treatments to mobilize stem cells, and may be used in peripheral blood stem cell transplantations for the treatment of ischemic disease of the lower extremities. Furthermore, it represents a mature method of mobilization. Generally, 4-5 days after the administration of $\mathrm{G}-\mathrm{CSF}$, the number of $\mathrm{CD} 34^{+}$cells in the peripheral blood can reach 40 - to 80 -fold of that prior to mobilization; however, if the administration of G-CSF is discontinued for 1 week, the number of $\mathrm{CD}_{34}{ }^{+}$cells in the peripheral blood is gradually restored to the baseline level. In addition, G-CSF can mobilize bone marrow-derived EPCs into the peripheral blood circulation and promote the angiogenesis in the ischemic area.

In summary, the results of the present study demonstrate that treating ischemia of the lower extremities with recombinant human G-CSF-mobilized peripheral blood stem cell transplantation is able to effectively increase the blood supply of the lower extremities in patients with diabetic foot. In the short term following stem cell transplantation, pain in the affected limb was relieved and the cold sensations in the limbs were gradually mitigated. Clinical symptoms were evidently improved and the ulcers healed gradually. The quality of life of the patients improved notably. Thus, we suggest that the improvement of blood supply in the short term may result from the locally increased quantities of blood caused by the aseptic inflammation following transplantation, while the continuous improvement in the local blood supply of the patients may be associated with EPC-related angiogenesis. Two dosages of G-CSF (5 and $10 \mu \mathrm{g} / \mathrm{kg} /$ day) were used to mobilize the stem cells for 4-7 days in this study. The adverse reactions that occurred in the process of mobilization and the collection stage, including mild pain, were within tolerable limits for the patients. Furthermore, no adverse reaction was observed during the clinical follow-up. The application of 5 and $10 \mu \mathrm{g} / \mathrm{kg} / \mathrm{day}$ G-CSF for 4 or 5 days may be a clinically useful approach, therefore, for the mobilization and gathering of stem cells.

\section{Acknowledgements}

This study was supported by the 2012 Plan Projects of the Development of Science and Technology of Weifang City (no. 20121188).

\section{References}

1. Tepper OM, Galiano RD, Kalka C and Gurtner GC: Endothelial progenitor cells: The promise of vascular stem cells for plastic surgery. Plast Reconstr Surg 111: 846-854, 2003.
2. Shintani S, Murohara T, Ikeda H, Ueno T, Honma T, Katoh A, Sasaki K, Shimada T, Oike Y and Imaizumi T: Mobilization of endothelial progenitor cells in patients with acute myocardial infarction. Circulation 103: 2776-2779, 2001.

3. Tepper OM, Galiano RD, Capla JM, Kalka C, Gagne PJ, Jacobowitz GR, Levine JP and Gurtner GC: Human endothelial progenitor cells from type II diabetics exhibit impaired proliferation, adhesion and incorporation into vascular structures. Circulation 106: 2781-2786, 2002.

4. Tavakoli M, Boulton AJ, Efron N and Malik RA: Increased Langerhan cell density and corneal nerve damage in diabetic patients: Role of immune mechanisms in human diabetic neuropathy. Cont Lens Anterior Eye 34: 7-11, 2011.

5. Georgiadis GS, Georgakarakos EI, Antoniou GA, Panagoutsos S, Argyriou C, Mourvati E, Passadakis P and Lazarides MK: Correlation of pre-existing radial artery macrocalcifications with late patency of primary radiocephalic fistulas in diabetic hemodialysis patients. J Vasc Surg 60: 462-470, 2014.

6. Pittengey MF, Mackay AM, Beck SC, Jaiswal RK, Douglas R, Mosca JD, Moorman MA, Simonetti DW, Craig S and Marshak DR: Multilineage potential of adult human mesenchymal stem cells. Science 284: 143-147, 1999.

7. Thomson JA, Itskovitz-Eldor J, Shapiro SS, Waknitz MA, Swiergiel JJ, Marshall VS and Jones JM: Embryonic stem cell lines derived from human blastocysts. Science 282: 1145-1147, 1998.

8. Lawall H, Bramlage P and Amann B: Treatment of peripheral arterial disease using stem and progenitor cell therapy. J Vasc Surg 53: 445-453, 2011.

9. Duong Van Huyen JP, Smadia DM, Bruneval P, Gaussem P, Dal-Cortivo L, Julia P, Fiessinger JN, Cavazzana-Calvo M, Aiach $\mathrm{M}$ and Emmerich J: Bone marrow-derived mononuclear cell therapy induces distal angiogenesis after local injection in critical leg ischemia. Modern Pathol 21: 837-846, 2008.

10. Li H, Chen X, Zhou B, Feng L, Xiao P and Wu W: Stem cell mobilization and collection for autologous peripheral blood stem cells transplantation in diabetic foot treatment. Zhong Guo $\mathrm{Zu}$ Zhi Gong Cheng Yan Jiu Yu Lin Chuang Kang Fu 15: 8508-8512, 2011 (In Chinese).

11. To LB, Haylock DN, Simmons PJ and Juttner CA: The biology and clinical uses of blood stem cells. Blood 89: 2233-2258, 1997.

12. Kalka C, Masuda H, Takahashi T, Kalka-Moll WM, Silver M, Kearney M, Li T, Isner JM and Asahara T: Transplantation of ex vivo expanded endothelial progenitor cells for therapeutic neovascularization. Proc Natl Acad Sci USA 97: 3422-3427, 2000.

13. Ahmad W, Khan IA, Ghaffar S, Al-Swailmi FK and Khan I: Risk factors for diabetic foot ulcer. J Ayub Med Coll Abbottabad 25: 16-18, 2013.

14. Alberti KG and Zimmet PZ: Definition, diagnosis and classification of diabetes mellitus and its complications. Part 1: Diagnosis and classification of diabetes mellitus provisional report of a WHO consultation. Diabet Med 15: 539-535, 1998.

15. Asahara T, Murohara T, Sullivan A, Silver M, van der Zee R, Li T, Witzenbichler B, Schatteman G and Isner JM: Isolation of putative progenitor endothelial cells for angiogenesis. Science 275: 964-967, 1997.

16. Yamamoto K, Kondo T, Suzuki S, Izawa H, Kobayashi M, Emi N, Komori K, Naoe T, Takamatsu J and Murohara T: Molecular evaluation of endothelial progenitor cells in patients with ischemic limbs: Therapeutic effect by stem cell transplantation. Arterioscler Thromb Vasc Biol 24: e192-e196, 2004.

17. Kim J, Kim M, Jeong Y, Lee WB, Park H, Kwon JY, Kim YM, Hwang D and Kwon YG: BMP9 induces cord blood-derived endothelial progenitor cell differentiation and ischemic neovascularization via ALK1. Arterioscler Thromb Vasc Biol 35: 2020-2031, 2015

18. Liang CJ, Shen WC, Chang FB, Wu VC, Wang SH, Young GH, Tsai JS, Tseng YC, Peng YS and Chen YL: Endothelial progenitor cells derived from Wharton's jelly of human umbilical cord attenuate ischemic acute kidney injury by increasing vascularization and decreasing apoptosis, inflammation, and fibrosis. Cell Transplant 24: 1363-1377, 2015.

19. Urbich C and Dimmeler S: Endothelial progenitor cells: Characterization and role in vascular biology. Circ Res 95: 343-353, 2004

20. Schatteman GC and Awad O: Hemangioblasts, angioblasts and adult endothelial cell progenitors. Anat Rec A Discov Mol Cell Evol Biol 276: 13-21, 2004. 
21. Rousseau B, Larrieu-Lahargue F, Bikfalvi A and Javerzat S: Involvement of fibroblast growth factors in choroidal angiogenesis and retinal vascularization. Exp Eye Res 77: 147-156, 2003.

22. Gluckman E and Rocha V: History of the clinical use of umbilical cord blood hematopoietic cells. Cytotherapy 7: 219-227, 2005.

23. Lu D, Chen B, Liang Z, Deng W, Jiang Y, Li S, Xu J, Wu Q, Zhang Z, Xie B and Chen S: Comparison of bone marrow mesenchymal stem cells with bone marrow-derived mononuclear cells for treatment of diabetic critical limb ischemia and foot ulcer: A double-blind, randomized, controlled trial. Diabetes Res Clin Pract 92: 26-36, 2011.

24. Tateishi-Yuyama E, Matsubara H, Murohara T, Ikeda U, Shintani S, Masaki H, Amano K, Kishimoto Y, Yoshimoto K, Akashi $\mathrm{H}$ et al; Therapeutic Angiogenesis using Cell Transplantation (TACT) Study Investigators: Therapeutic angiogenesis for patients with limb ischaemia by autologous transplantation of bone marrow cells: A pilot study and a randomized controlled trial. Lancet 360: 427-435, 2002.

25. Quirici N, Soligo D, Caneva L, Servida F, Bossolasco P and Deliliers GL: Differentiation and expansion of endothelial cells from human bone marrow CD133(+) cells. Br J Haematol 115: 186-194, 2001.
26. Pesce M, Orlandi A, Iachininoto MG, Straino S, Torella AR, Rizzuti V, Pompilio G, Bonanno G, Scambia G and Capogrossi MC: Myoendothelial differentiation of human umbilical cord blood derived stem cells in ischemic limb tissues. Circ Res 93: 51-62, 2003.

27. Alonso S, Cabrero M, Caballero JC, Dávila J, de la Calle VG, López-Godino O, López-Corral L, Pérez E, Vázquez L, Corral R, et al: Acute graft-versus-host disease and bronchiolitis obliterans after autologous stem cell transplantation in a patient with multiple myeloma. Clin Case Rep 3: 370-375, 2015.

28. Hayase T, Morimoto A, Kawahara Y, Yagi M, Kanai N, Nobusawa S, Hirato J and Gomi A: An infant with medulloepithelioma successfully treated by high-dose chemotherapy followed by autologous peripheral blood stem cell transplantation without radiotherapy. J Pediatr Hematol Oncol 37: e394-e398, 2015.

29. Eid KA, Miranda EC and Aguiar Sdos S: Mobilization and collection of CD34(+) cells for autologous transplantation of peripheral blood hematopoietic progenitor cells in children: analysis of two different granulocyte-colony stimulating factor doses. Rev Bras Hematol Hemoter 37: 160-166, 2015. 